\title{
BMJ Open How do health professionals translate evidence on early childhood allergy prevention into health literacy- responsive practice? A protocol for a mixed-method study on the views of German health professionals
}

\author{
Janina Curbach (D) , ${ }^{1,2}$ Jonas Lander (D) , ${ }^{3}$ Marie Luise Dierks (D),$^{3}$ \\ Eva-Maria Grepmeier (D) ,' Julia von Sommoggy
}

To cite: Curbach J, Lander J, Dierks ML, et al. How do health professionals translate evidence on early childhood allergy prevention into health literacy-responsive practice? A protocol for a mixed-method study on the views of German health professionals. BMJ Open 2021;11:e047733. doi:10.1136/ bmjopen-2020-047733

- Prepublication history and additional supplemental material for this paper are available online. To view these files, please visit the journal online (http://dx.doi.org/10.1136/ bmjopen-2020-047733).

Received 07 December 2020 Accepted 13 October 2021

Check for updates

(c) Author(s) (or their employer(s)) 2021. Re-use permitted under CC BY-NC. No commercial re-use. See rights and permissions. Published by BMJ.

For numbered affiliations see end of article.

Correspondence to Janina Curbach; janina.curbach@ukr.de

\section{ABSTRACT}

Introduction Paediatricians, general practitioners (GPs) and midwives in primary care are important sources of information for parents on early childhood allergy prevention (ECAP). Research has shown that preventive counselling by health professionals can be effective in improving patients' health literacy ( $\mathrm{HL}$ ) and health behaviour. Providing effective advice relies on two factors. First, health professionals need be upto-date with research evidence on ECAP, to consider popular misconceptions and fears and to translate this knowledge into clear recommendations for parents (knowledge translation). Second, they need to know and apply counselling techniques and create a practice setting which accommodates parental HL needs (health literacy-responsive care). The objective of this study is to explore and assess how German health professionals take up and translate ECAP evidence into appropriate recommendations for parents, how they consider $\mathrm{HL}$ in counselling and practice organisation and what barriers and enablers they find in their performance of $\mathrm{HL}$ responsive ECAP.

Methods and analysis The study has a sequential mixed-method design, in two phases. In the first phase, qualitative semi-structured expert interviews will be conducted with health professionals (paediatricians, GPs and midwives) at primary care level and professional policy level. Data collection is ongoing until January 2022. In the second phase, based on the qualitative results, a standardised questionnaire will be developed, and pilot-tested in a wider population of German health professionals. The findings of both phases will be integrated.

Ethics and dissemination The study has received ethical approval from the Ethics Committee of the University of Regensburg (18-1205-101). The results will be published in international peer-reviewed open access journals and via presentations at scientific conferences. The results will also be shared with German health professionals, decision-makers and potential funders of interventions.

\section{Strengths and limitations of this study}

- First study of German health professionals' experiences with translating scientific evidence into understandable recommendations for parents in primary care.

- First study of health professionals' views on health literacy $(\mathrm{HL})$ and $\mathrm{HL}-$-responsive care in Germany in primary care.

- Results will reveal potential for enhancing HLresponsive care and will inform interventions aimed at increasing $\mathrm{HL}$ awareness and $\mathrm{HL}$ responsiveness of health professionals in patient counselling and early childhood allergy prevention.

- Readiness to participate may be lower in health professionals who do not feel confident/experienced enough to perform HL-responsive counselling.

- Purposeful sampling for the qualitative interviews allows for capturing a great variety of views; however, it will not generate representative or generalisable findings.

\section{INTRODUCTION}

Health professionals' role in early childhood allergy prevention

In Germany, paediatricians, general practitioners (GPs) and midwives in primary outpatient care are important sources of information on infant feeding, hygiene and early childhood allergy prevention (ECAP) for expectant and new parents.

These health professionals have regular contact with parents: more than $90 \%$ of families use the paediatric health screening programme (U-examinations) for children younger than 2 years, ${ }^{1}$ which is usually performed by paediatricians, but can also be conducted by GPs. In addition, German 
mothers with statutory health insurance are entitled to prebirth and postbirth care by midwives, which in Bavaria is used by $65 \%$ of mothers prebirth and $94.9 \%$ postbirth. ${ }^{2}$ Midwives also offer antenatal education courses about childbirth and parenthood for pregnant women and their partners. These courses cover breastfeeding and infant care ${ }^{3}$ and therefore are relevant to ECAP. ${ }^{4}$

When counselling parents on ECAP, a health professional should advise them, for example, to keep the home smoke-free, to avoid mildew growth and to introduce solid food gradually after at least 4 months of exclusive breastfeeding. ${ }^{5}$ Children from high-risk families should be fed with hydrolysed formula if breastfeeding is not possible, they should be vaccinated in the same way as lower-risk children, and high-risk families should not have a pet cat. ${ }^{5}$ Health professionals are expected to help their patients adhere to these recommendations. However, allergy prevention may pose a special challenge to health professionals in terms of health literacy (HL)responsive and evidence-based counselling of parents, for two reasons: First, the evidence on risk factors for childhood allergy changes quickly due to high research activity in the field. For example, while former guidelines have recommended avoidance of allergens (eg, nuts) and delayed introduction of some solid foods, the current guidelines emphasise that parents do not need to take any specific preventive action regarding diet. ${ }^{5}$ Second, scientific evidence on ECAP is socially contested by a variety of non-scientific myths and beliefs around infant feeding and allergy prevention. Studies have highlighted that feeding practices of new mothers are influenced by misinformation about breastfeeding, cultural expectations and stigma or by moralising ideologies. ${ }^{67}$ Likewise, gaps in knowledge about pathogenesis of allergy have allowed outdated ideas to persist, and new myths have emerged from misleading stories in the news and social media, and from product marketers taking advantage of uncertainty. ${ }^{8-11}$ Health professionals may thus also need to dissuade parents from taking (potentially harmful) actions based on misinformation and fears.

Research has shown that preventive counselling by health professionals can be effective in improving patients' HL and health behaviour, for example, with regard to smoking cessation and physical activity. ${ }^{12-14}$ Primary care interventions which explicitly promote HL aimed at modifying lifestyle risk factors (eg, nutrition) were also successful in achieving behaviour changes, as demonstrated in a systematic review. ${ }^{12}$ There is as yet no data available for the German healthcare context.

To provide effective advice on ECAP, health professionals must:

- Be up-to-date with research evidence on ECAP, consider popular misconceptions and fears and translate this knowledge into clear recommendations for their patients' families (knowledge translation).

- Know and use counselling techniques that respond to parental HL needs and create a HL-supportive practice setting (HL-responsive care).
The following paragraphs describe these two aspects in detail.

\section{Knowledge uptake and translation}

In order to understand how ECAP-specific evidence and recommendations affect daily practice, we need to know how health professionals learn about the current state of the scientific discussion, and how they translate this information into HL-responsive recommendations for parents. Research on the implementation of evidencebased care offers two theoretical perspectives on this process: some studies focus on identifying barriers to and enablers of knowledge dissemination in health professionals' daily practice (medical and behavioural sciences perspective), ${ }^{15-17}$ while others focus on understanding how health professionals make sense of the evidence and how they engage in the social construction of practical expert knowledge (social sciences perspective) ${ }^{18} 19$ From the latter perspective, health professionals incorporate a variety of situational determinants, contextual conditions and tacit knowledge, as well as colleagues' and patients' experiences, when trying to make sense of the evidence available. ${ }^{19-23}$ This process is also conceptualised as a 'construction of mindlines, ${ }^{20}{ }^{21}$ in social 'communities of practice'. ${ }^{24}$ In the current study, we embrace both theoretical approaches. A survey of German health professionals' acceptance of recommendations on infant nutrition ${ }^{25}$ seems to support the social constructivist view of knowledge translation: the midwives surveyed said that it was more important for them to consider families' individual situations than to strictly adhere to guidelines.

Apart from this, we do not know how German health professionals gain access to, make sense of and translate into practice the evidence and recommendations available on ECAP.

\section{Health literacy-responsive care}

It is broadly recommended that HL be addressed as part of each clinical encounter, to improve patient outcomes. ${ }^{26}$ A variety of guidelines on HL-responsive care aim to assist this process. Studies show that different communication techniques help to meet the needs of patients with low $\mathrm{HL},{ }^{27-30}$ for example, avoiding medical jargon, breaking down information to smaller, more manageable components and using the teach-back method, inviting patients to explain key information in their own words. ${ }^{26} 31$ Organisations such as the American Medical Association endorse 'universal HL precautions', that is, using easyto-understand terms with all patients instead of focusing only on those with low literacy, ${ }^{2632}$ as patients with low HL may be difficult to identify. ${ }^{33}$ Indeed, a systematic review found that many health professionals had a poor understanding of HL, and only a small percentage felt able to identify patients with low HL. Barriers cited to responding to low HL were time constraints and lack of educational resources. ${ }^{34}$ US studies found that physicians often overlook HL in routine care, overestimating patients' HL skills. ${ }^{32}{ }^{34}$ In response, several studies suggest or employ 


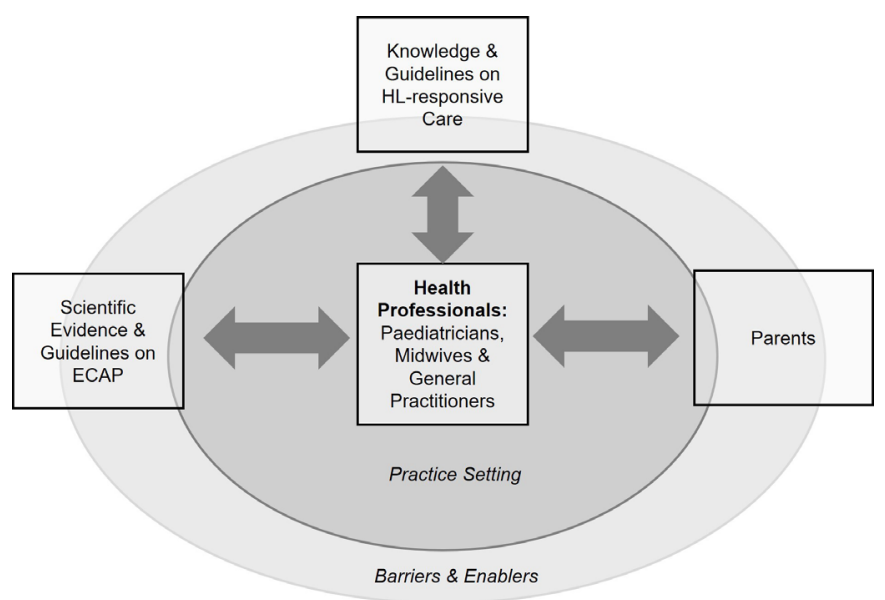

Figure 1 Schematic illustration of aspects relevant in ECAP counselling by health professionals.

curricula for professional training. ${ }^{27}$ 35-38 Beyond these individual-level approaches, care environments, that is, the paediatrician's or midwife's office, could be made more HL-responsive, for example, by fostering communication, inviting questions ${ }^{2639-42}$ and by creating a 'shamefree' care environment, for example by improving the team's attitudes to patient-centred care. ${ }^{31} 33$ Despite the proven relevance of HL-responsive care and care settings for improving HL and health outcomes in patients, addressing HL is still not a routine part of healthcare delivery.

For the German context, and for ECAP-related HL, it is still unclear how health professionals consider HL in routine care, and what their views are on responding to and supporting parental HL.

In summary, improved HL in ECAP requires the support of primary care health professionals to translate scientific evidence into understandable recommendations and support parents' allergy-related HL. ${ }^{26} 4042$ To make the most of this support, we need to better understand how evidence is taken up and translated by health

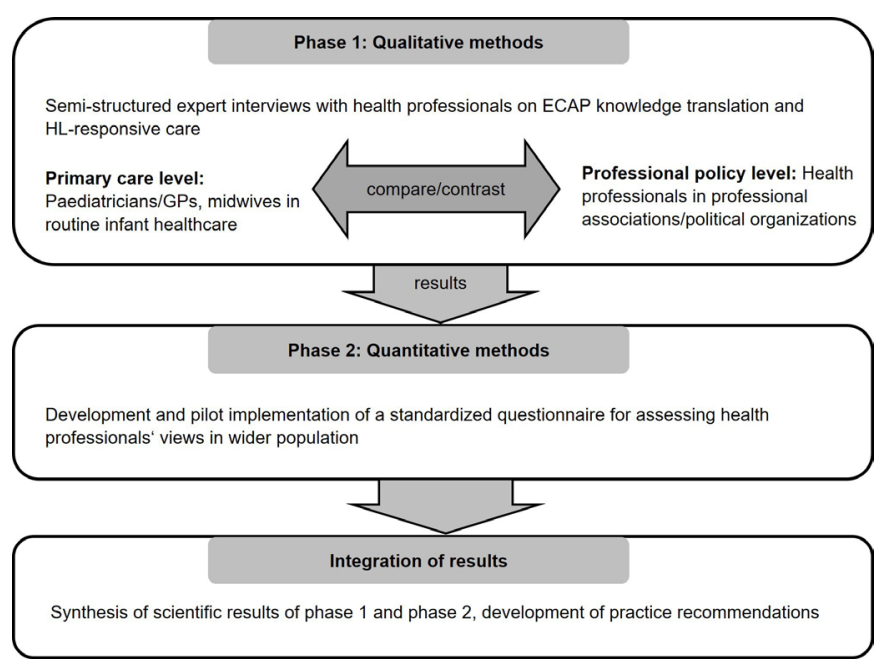

Figure 2 Visual overview of the sequential mixed-method study design. professionals into practical knowledge, to understand their views and practices with regard to ECAP counselling and parental HL and to explore perceived barriers and enablers in their daily practice.

\section{Objectives}

This study aims to explore and assess how health professionals (figure 1):

- Inform themselves about ECAP.

- Make sense of the available research evidence.

- Translate this evidence into understandable recommendations for counselling parents.

- Experience HL challenges in ECAP counselling.

- Express their views on HL, HL-responsive care and their experiences with using HL-sensitive counselling techniques and with creating a HL-supportive care setting.

- Describe barriers to and enablers of ECAP knowledge translation and in HL-sensitive and HL-supportive patient counselling.

\section{METHODS AND ANALYSIS \\ Study design}

This study has a sequential mixed-method design ${ }^{43}$ with two consecutive phases (see figure 2). The total duration of the study is 36 months, with the first study phase lasting 24 months from project start in February 2020, and the subsequent phase 2 another 12 months up until March 2023. Qualitative data collection is ongoing until 31 January 2022.

\section{Patient and public involvement:}

Health professionals did not take part in the study design, but are involved via informal consultations in further developing the interview guides and recruitment strategies during the research process. In the integration and dissemination phase, we are planning to discuss the result with health professionals in order to jointly develop future research projects and interventions.

\section{Phase 1}

Qualitative exploratory methods will be applied in phase 1 , owing to the current lack of research in the area. Semistructured expert interviews will be conducted at two levels: (a) with primary care health professionals (paediatricians, GPs and midwives) who work in private practices (primary care level), and (b) with (health) professionals who hold a functional position in a professional association or organisation dealing with HL and/or ECAP on a strategic level (professional policy level). We hope by considering both levels to gain greater insight.

\section{Phase 2}

The qualitative results of phase 1 will provide the basis for developing and pilot testing a standardised questionnaire with paediatricians, GPs and midwives. The questionnaire will systematically assess (a) ECAP and HL practices of the health professionals, and (b) perceived barriers and 
enablers of the health professionals regarding HL-responsive counselling.

The qualitative and quantitative results of phase 1 and phase 2 will be integrated at the end of the study in order to generate recommendations for interventions to enhance HL-responsive counselling in ECAP, as well as to develop a study design for further implementation of the assessment tool.

The study is part of the multicentre research unit 'Health Literacy in Early Childhood Allergy Prevention' (HELICAP), which uses the example of ECAP to enhance the understanding of HL as a public health goal (https:/ / www.helicap.org/en/home).

\section{Phase 1: exploring health professionals' views on ECAP knowledge translation and $\mathrm{HL}-$ responsive care \\ Primary care level: participants and sampling/recruitment Participants}

Eligible study participants are German health professionals in primary care who perform routine paediatric/infant healthcare in private practice - that is, prenatal and postnatal follow-up care (midwives) and the national child health screening programme of 'U-examinations' (paediatricians/GPs). We intend to include health professionals from two German provinces, one in the northern part of the country (Lower Saxony) and one in the South (Bavaria). Health professionals with less than 2 years of professional experience are excluded, because we assume that is a necessary minimum to be able to report on routine counselling experiences and challenges in dayto-day care.

\section{Sampling and recruitment}

Initially, we will identify and recruit study participants via three routes: from pre-existing personal contacts of the research group, by cold calling and by recruiting agents in professional associations. We intend to use a purposive sampling strategy to obtain a great diversity of perspectives (for details cf. table 1). Subsequent snowballing recruitment will occur along with this purposive sampling strategy. ${ }^{445}$

\begin{tabular}{|c|c|}
\hline Inclusion criteria & Description \\
\hline Catchment area & $\begin{array}{l}\text { Rural vs } \\
\text { urban }\end{array}$ \\
\hline Specialisation & $\begin{array}{l}\text { Specialised in allergies vs } \\
\text { no specialisation }\end{array}$ \\
\hline Form of practice & $\begin{array}{l}\text { Single vs } \\
\text { group }\end{array}$ \\
\hline Gender & $\begin{array}{l}\text { Male vs } \\
\text { female }\end{array}$ \\
\hline Professional experience & $\begin{array}{l}15 \text { year +vs } \\
\text { less than } 15 \text { years }\end{array}$ \\
\hline
\end{tabular}

In urban areas, the variety of patients' background is expected to be greater in terms of socioeconomic status, ethnicity, and, since the prevalence of allergic conditions is higher in urban settings, parental information needs are expected to be different than in rural areas. ${ }^{46} 47$

\section{Professional policy level: participants and sampling/ recruitment \\ Participants}

We will also conduct qualitative expert interviews with health professionals who hold a position in a professional association or political organisation, and who are responsible for (or have a leadership function in) either HL or ECAP in terms of policy, education and training of health professionals, guideline development or specific HL-related projects. These expert interviews will provide a strategic perspective on health professionals' roles and potential in HL-responsive ECAP, which is valuable to contrast with the views of health professionals responsible for day-to-day healthcare.

\section{Sampling and recruitment}

We will identify relevant professional associations and organisations for physicians, midwives and public health in general (eg, State Associations of Physicians/Midwives, National Action Plan on Health Literacy), and subsequently identify and recruit representatives who have a special responsibility for either HL or ECAP. Recruitment will occur via cold calling and pre-existing contacts of the HELICAP research group members.

For all interviews, financial incentives for participation will be offered. Recruitment will be continued until thematic saturation is achieved in analysis, which we expect to be achieved by a sample size of about $n=20$ in each of the health professional groups in primary care, and by a sample size of about $\mathrm{n}=10$ on the professional policy level, respectively. ${ }^{48}$

\section{Data collection}

Conducting expert interviews is a common qualitative method in public health research, including studies on HL. ${ }^{490}$ The interviews will draw on the experts' specific experience and knowledge resulting from their daily practice and professional position. When planning the study, the interviews were originally intended to be conducted face to face; however, due to the COVID-19 pandemic and infection prevention measures (social distancing and travel restrictions), we switched to telephone interviews. All qualitative interviews in phase 1 will be led by two experienced members of the research team and will last about $45 \mathrm{~min}$.

\section{Primary care level}

The interview guide for the expert interviews on primary care level has been developed based on literature search as well as informal consultations with paediatricians/ GPs, and midwives (see online supplemental appendix). 
The interview guide starts with an open prompt, asking the interviewee to provide a narrative account of their personal experience with counselling parents on ECAP, and then continues with semi-structured questions covering the following topics:

- Personal practice of searching for, studying and making sense of available evidence on ECAP.

- ECAP knowledge translation into recommendations, knowledge transfer to parents.

- Views on and experiences with counselling parents on ECAP in daily care.

- Awareness of and views on HL-responsive care and counselling (techniques).

- Awareness of and views on creating a HL-responsive practice setting.

- Perceived barriers and enablers regarding knowledge translation and HL-responsive counselling on ECAP.

The first draft of the interview guide will be pretested with paediatricians/GPs and midwives $(\mathrm{n}=2 \mathrm{each})$ and revised accordingly. A standardised data sheet will be developed to collect relevant sociodemographic data of the interviewees (ie, age, gender, length of professional experience) as well as characteristics of the practice setting (ie, single vs group practice, specifics about the catchment area, specifications in practice profile).

\section{Professional policy level}

The interview guides for the interviews on professional policy level will be developed based on further literature searches, field knowledge of the research team and insights from the interviews on primary care level. Depending on the interviewees' position and expertise, the interview guide will focus either on HL or on ECAP, and/or on training of physicians or midwives, etc. The guides will encompass semi-structured questions covering the following topics:

- Role and responsibility of health professionals (midwife or physician, depending on sample) in ECAP or HL, respectively.

- Challenges of knowledge translation in ECAP/challenges of HL-responsive care.

- View on feasible HL practices/ECAP counselling in daily care.

- Needs for action (policies, education/training, structures, resources).

\section{Data analysis}

All interviews will be audio-recorded and transcribed verbatim with participants' permission. Data will be analysed using computer-assisted qualitative data analysis software (ATLAS.ti, V.7), based on structuring qualitative content analysis. ${ }^{51}$ This approach allows for discovering newly emerging themes via open coding ('inductive category formation'). ${ }^{5152}$ Two experienced researchers will repeatedly read, code and analyse the transcripts, structuring the data into overarching themes as predefined in the interview guide, while at the same time identifying emergent themes in the data. Differences in coding between the researchers will be discussed until consensus is reached. Themes will then be grouped into higher-level categories.

Analysis of the expert interviews on the professional policy level will be performed as for the interviews with health professionals in primary care.

Finally, we will contrast the views of professionals in a leadership role with the views of those who report from day-to-day interaction with patients. Thereby, we intend to compare and contrast the positions in order to elicit potential consensus, (mis) understandings and mutual expectations.

All results of the qualitative study phase will be prepared for publication according to the consolidated criteria for reporting qualitative research-standards for reporting on qualitative research results. ${ }^{53}$

\section{Phase 2: developing and pilot testing a standardised questionnaire and study design}

The subsequent study phase depends on the findings from phase 1 (sequential-dependent study design). Following a 'building approach' for integrating qualitative and quantitative data at methods level in the mixedmethod design, the results of the qualitative study phase will inform the proceedings and content of the second study phase, ${ }^{54}$ that is, the development and testing of a standardised questionnaire. The pilot test aims to evaluate the usability of the questionnaire and the process of data collection. We aim to apply the results of phase 2 for a representative survey in a follow-up project.

\section{Participants, eligibility criteria, recruitment and sampling}

The participants will be chosen by random sampling from all health professionals registered in Bavaria (Southern German province). As of 2019, there are $\mathrm{n}=1140$ paediatricians, $n=2850$ midwives and $n=9343$ GPs registered in Bavaria. We will sample only primary care professionals who work in private practice, and only GPs who perform infant screening examinations (cf. eligibility of participants of phase 1).

Assessment tool development and data collection in pilot test When developing the assessment tool, items will be generated based on results of phase 1, in order to capture barriers and enablers. The questionnaire will be checked for face validity and tested for comprehensibility, comprehensiveness and relevance in a pretest with three representatives of each health professional group (paediatricians, midwives and GPs). The think-aloud method will be applied when the interviewed person fills in the questionnaire..$^{556}$

The (mail) questionnaire will be distributed among $n=100$ participants of each of the three health professional groups (paediatricians, GPs and midwives). Special efforts will be needed to ensure high response rates, since survey return rates for health professionals, above all physicians, tend to be very low. ${ }^{25} 5758$ We will therefore draw on Dillman's total design method, which recommends 
to create a relationship of reciprocity with respondents, to lower their investment and maximise their rewards (eg, by offering incentives) and to include repeated nonresponder follow-up mailings. ${ }^{59-61}$ The researchers will document each step in a semi-standardised documentation sheet, including time, effort, effectiveness and feasibility of procedures. The data collected will be converted into a data set using the statistical software SPSS.

\section{Data analysis and revision of study design and questionnaire}

The collected data of the pilot surveys will be analysed, for example, regarding completeness and frequency of missing values using statistical software (SPSS, V.25). Free-text responses will be analysed for incomprehensible or misleading items and variance of the responses. The implementation of the questionnaire will be evaluated regarding response rates (overall and within the three groups of health professionals), the duration from first contact to response and the number of contacts needed. Based on the statistical data analysis and the documentation sheet, strengths and weaknesses of the study design and questionnaire will be assessed. A revised study protocol and questionnaire will be generated. These tools are intended to guide a representative questionnaire survey, which is planned for a second funding phase after the end of this 3-year research study, and which is meant to test the generalisability of the findings of this research study.

\section{Integration of results}

The research team will integrate the findings of the qualitative and quantitative study phases at two points. First, the design and contents of the quantitative study, for example, questionnaire items, will be developed according to the results of the qualitative study phase ('building approach', see methods section). Second, at the end of the study, we will integrate the qualitative and quantitative findings at the interpretation and reporting level. ${ }^{54}$ While parts of the qualitative and quantitative results will be published and presented separately during the course of the study, theme-based parts of the qualitative and quantitative results will be reported jointly at the end, using three types of outputs. First, a deeper understanding of themes and challenges, barriers and enablers. Second, practice recommendations for interventions aimed at enhancing health professionals' skills. Third, based on the qualitative and quantitative insights, we will finalise the pilot-tested assessment tool and study design in preparation of a larger-scale representative survey.

\section{ETHICS AND DISSEMINATION}

Ethical considerations and informed consent:

The study has received ethical approval from the Ethics Committee of the University of Regensburg (181205-101). This study complies with the Declaration of Helsinki. ${ }^{62} 63$
Participation in the study will only be possible after providing informed consent to the audio recording and scientific use of the interviews. All of the study information and informed consent documents which will be handed out to study participants have been approved by the ethics committee of the University of Regensburg.

\section{Confidentiality and data protection}

The transcripts will be deidentified with regard to names and cities: names will be replaced by an ID number, and personal identifiers will be removed early on during transcription and analysis. All persons involved in collecting, transcribing and analysing the data will be trained in procedures to protect the participants' privacy and confidentiality and are bound by the Data Protection Act (DSGVO). When disseminating findings from the research study, direct quotes from respondents may be used as an example and will remain anonymous.

All databases and the software used are stored on secure servers of the University of Regensburg. Audiotapes, transcriptions and notes will be kept in a secure, locked location to which only authorised persons will have access. A numbered hard copy of the transcriptions will be retained, to provide for easy follow-up in the case of questions, and an additional electronic copy will be stored so that it can be used for data confirmation and/or audits. In accordance with the rules of good scientific practice, the qualitative research data (audio data and transcripts) will be archived in the Department of Epidemiology and Preventive Medicine of the University of Regensburg for at least 10 years.

\section{Output, dissemination and outlook}

The results of this study will be published in international peer-reviewed open access journals and via oral and poster presentations at national and international scientific conferences. We will also disseminate results via presentations and workshops with German health professionals, decision-makers and potential funders of interventions (eg, health insurance providers).

\section{Author affiliations}

${ }^{1}$ Department of Epidemiology and Preventive Medicine/Medical Sociology, University of Regensburg Faculty of Medicine, Regensburg, Germany

${ }^{2}$ Faculty of Businesss Studies, Ostbayerische Technische Hochschule (OTH) Regensburg, Regensburg, Germany

${ }^{3}$ Department of Epidemiology, Social Medicine and Health Systems Research, Hannover Medical School, Hannover, Germany

Contributors JC conceptualised the study. JvS, JL and MLD contributed to further development of the study design. JC drafted the first version of the manuscript and finalised it. JvS, E-MG, JL and MLD revised the manuscript. All authors approved the final version.

Funding This research study is funded by the German Research Foundation (DFG, grant number: FOR 2959 CU 438/1-1) and is a subproject of the HELICAP Research Group on ECAP-related HL (www.helicap.org).

Competing interests None declared.

Patient consent for publication Not required.

Provenance and peer review Not commissioned; externally peer reviewed. 
Supplemental material This content has been supplied by the author(s). It has not been vetted by BMJ Publishing Group Limited (BMJ) and may not have been peer-reviewed. Any opinions or recommendations discussed are solely those of the author(s) and are not endorsed by BMJ. BMJ disclaims all liability and responsibility arising from any reliance placed on the content. Where the content includes any translated material, BMJ does not warrant the accuracy and reliability of the translations (including but not limited to local regulations, clinical guidelines, terminology, drug names and drug dosages), and is not responsible for any error and/or omissions arising from translation and adaptation or otherwise.

Open access This is an open access article distributed in accordance with the Creative Commons Attribution Non Commercial (CC BY-NC 4.0) license, which permits others to distribute, remix, adapt, build upon this work non-commercially, and license their derivative works on different terms, provided the original work is properly cited, appropriate credit is given, any changes made indicated, and the use is non-commercial. See: http://creativecommons.org/licenses/by-nc/4.0/.

\section{ORCID iDs}

Janina Curbach http://orcid.org/0000-0003-4460-233X

Jonas Lander http://orcid.org/0000-0003-4960-3307

Marie Luise Dierks http://orcid.org/0000-0002-0225-6048

Eva-Maria Grepmeier http://orcid.org/0000-0001-5043-0728

Julia von Sommoggy http://orcid.org/0000-0001-7869-7459

\section{REFERENCES}

1 Robert Koch Institut. Participation in early detection check-ups for children, 2015.

2 IGES Institut. Studie Zur Hebammenversorgung Im Freistaat Bayern, 2018.

3 Gagnon AJ, Sandall J. Individual or group antenatal education for childbirth or parenthood, or both. Cochrane Database Syst Rev 2007;3:CD002869.

4 Venter C, Clayton B, Dean T. Infant nutrition part 2: the midwife's role in allergy prevention. Br J Midwifery 2008;16:791-803.

5 Schäfer T, Bauer C-P, Beyer K, et al. S3-Guideline on allergy prevention: 2014 update: guideline of the German Society for Allergology and clinical immunology (DGAKI) and the German Society for pediatric and adolescent medicine (DGKJ). Allergo J Int 2014;23:186-99.

6 Altman DR, Chiaramonte LT. Public perception of food allergy. J Allergy Clin Immunol 1996:97:1247-51.

7 Newhook JT, Ludlow V, Newhook LA, et al. Infant-feeding among low-income women: the social context that shapes their perspectives and experiences. Can J Nurs Res 2013;45:28-49.

8 senseaboutscience. Making sense of allergies, 2015. Available: https://senseaboutscience.org/wp-content/uploads/2016/09/MakingSense-of-Allergies-1.pdf [Accessed 14 Dec 2018].

9 Waggoner MR. Parsing the peanut panic: the social life of a contested food allergy epidemic. Soc Sci Med 2013;90:49-55.

10 Colver A. Are the dangers of childhood food allergy exaggerated? BMJ 2006;333:494-6.

11 Shenker NS. The resurgent influence of big formula. BMJ 2018;362:k3577 https://www.bmj.com/content/362/bmj.k3577.full. pdf

12 Dennis S, Williams A, Taggart J, et al. Which providers can bridge the health literacy gap in lifestyle risk factor modification education: a systematic review and narrative synthesis. BMC Fam Pract 2012;13:44.

13 Berni Canani R, Leone L, D'Auria E, et al. The effects of dietary counseling on children with food allergy: a prospective, multicenter intervention study. J Acad Nutr Diet 2014;114:1432-9.

14 Gagliardi AR, Abdallah F, Faulkner G, et al. Factors contributing to the effectiveness of physical activity counselling in primary care: a realist systematic review. Patient Educ Couns 2015;98:412-9.

15 World Health Organisation (WHO). Bridging the "know-do" gap: meeting on knowledge translation in global health, 2006. Available: https://www.measureevaluation.org/resources/training/capacitybuilding-resources/high-impact-research-training-curricula/bridgingthe-know-do-gap.pdf [Accessed 14 Dec 2018].

16 Atkins L, Francis J, Islam R, et al. A guide to using the theoretical domains framework of behaviour change to investigate implementation problems. Implement Sci 2017;12:77.

17 Cabana MD, Ebel BE, Cooper-Patrick L, et al. Barriers pediatricians face when using asthma practice guidelines. Arch Pediatr Adolesc Med 2000;154:685-93.

18 Greenhalgh T, Howick J, Maskrey N, et al. Evidence based medicine: a movement in crisis? BMJ 2014;348:g3725.
19 Wieringa S, Greenhalgh T. 10 years of mindlines: a systematic review and commentary. Implement Sci 2015;10:45

20 Gabbay J, le May A. Evidence based guidelines or collectively constructed "mindlines?" Ethnographic study of knowledge management in primary care. BMJ 2004;329:1013.

21 Gabbay J, le May A. Mindlines: making sense of evidence in practice. Br J Gen Pract 2016;66:402-3.

22 Graham ID, Logan J, Harrison MB, et al. Lost in knowledge translation: time for a MAP? J Contin Educ Health Prof 2006;26:13-24.

23 Ferlie E, Fitzgerald L, Wood M. Getting evidence into clinical practice: an organisational behaviour perspective. $J$ Health Serv Res Policy 2000;5:96-102.

24 Wenger E. Communities of practice: learning, meaning and identity. Sixth edn. Cambridge: Cambridge University Press, 1998.

25 Reiss K, Flothkötter M, Greif NP. Gesundheitswesen. 2018: 80, 482-8.

26 Yin HS, Jay M, Maness L, et al. Health literacy: an educationally sensitive patient outcome. J Gen Intern Med 2015;30:1363-8.

27 Coleman CA, Hudson S, Maine LL. Health literacy practices and educational competencies for health professionals: a consensus study. J Health Commun 2013;18 Suppl 1:82-102.

28 Schwartzberg JG, Cowett A, VanGeest J, et al. Communication techniques for patients with low health literacy: a survey of physicians, nurses, and pharmacists. Am J Health Behav 2007;31 Suppl 1:S96-104.

29 Yin HS, Dreyer BP, van Schaick L, et al. Randomized controlled trial of a pictogram-based intervention to reduce liquid medication dosing errors and improve adherence among caregivers of young children. Arch Pediatr Adolesc Med 2008;162:814-22.

30 Yin HS, Gupta RS, Tomopoulos S, et al. A Low-Literacy asthma action plan to improve provider asthma counseling: a randomized study. Pediatrics 2016;137. doi:10.1542/peds.2015-0468. [Epub ahead of print: 0212 2015]

31 Abrams MA, Klass P, Dreyer BP. Health literacy and children: introduction. Pediatrics 2009;124 Suppl 3:S262-4.

32 Hersh L, Salzman B, Snyderman D. Health literacy in primary care practice. Am Fam Physician 2015;92:118-24.

33 Weiss BD, Schwartzberg JG, Association AM. Health literacy and patient safety: help patients understand. Manual for clinicians.: AMA Foundation, 2007

34 Rajah R, Ahmad Hassali MA, Jou LC, et al. The perspective of healthcare providers and patients on health literacy: a systematic review of the quantitative and qualitative studies. Perspect Public Health 2018;138:122-32.

35 Karuranga S, Sørensen K, Coleman C, et al. Health literacy competencies for European health care personnel. Health Lit Res Pract 2017;1:e247-56.

36 Kaper MS, Sixsmith J, Koot JAR, et al. Developing and pilot testing a comprehensive health literacy communication training for health professionals in three European countries. Patient Educ Couns 2018;101:152-8.

37 Coleman $\mathrm{C}$. Teaching health care professionals about health literacy: a review of the literature. Nurs Outlook 2011;59:70-8.

38 Coleman CA, Fromer A. A health literacy training intervention for physicians and other health professionals. Fam Med 2015;47:388-92.

39 Brach C, Dreyer BP, Schillinger D. Physicians' roles in creating health literate organizations: a call to action. J Gen Intern Med 2014;29:273-5.

40 Koh HK, Brach C, Harris LM, et al. A proposed 'health literate care model' would constitute a systems approach to improving patients engagement in care. Health Aff 2013;32:357-67.

41 Geboers B, Reijneveld SA, Koot JAR, et al. Moving towards a comprehensive approach for health literacy interventions: the development of a health literacy intervention model. Int J Environ Res Public Health 2018;15. doi:10.3390/ijerph15061268. [Epub ahead of print: 1506 2018].

42 Farmanova E, Bonneville L, Bouchard L. Organizational health literacy: review of theories, frameworks, guides, and implementation issues. Inquiry 2018;55:46958018757848.

43 Tashakkori A, Teddlie C. Integrating qualitative and quantitative approaches to research. In: Bickman L, Rog DJ, eds. The SAGE Handbook of applied social research methods. 2nd edn. Los Angeles: SAGE, 2009: 283-317.

44 Patton MQ. Qualitative research \& evaluation methods: Integrating theory and practice. Los Angeles, London, New Delhi, Singapore, Washington DC: SAGE, 2015.

45 Palinkas LA, Horwitz SM, Green CA, et al. Purposeful sampling for qualitative data collection and analysis in mixed method implementation research. Adm Policy Ment Health 2015;42:533-44. 
46 Thamm R, Peothko-Müller C, Hüther A. Allergic diseases in children and adolescents in Germany. Results of the cross-sectional KiGGS wave 2 study and trends. Journal of health monitoring 2018;3:3-18.

47 Schröder PC LJ, Wong GWK, et al. The rural-urban enigma of allergy: what can we learn from studies around the world? Pediatr Allergy Immunol 2015;26:95-102.

48 Saunders B, Sim J, Kingstone T, et al. Saturation in qualitative research: exploring its conceptualization and operationalization. Qual Quant 2018;52:1893-907.

49 Broda A, Bieber A, Meyer G, et al. Perspectives of policy and political decision makers on access to formal dementia care: expert interviews in eight European countries. BMC Health Serv Res 2017; $17: 518$.

50 Weishaar $\mathrm{H}$, Hurrelmann $\mathrm{K}$, Okan $\mathrm{O}$, et al. Framing health literacy: a comparative analysis of national action plans. Health Policy 2019;123:11-20.

51 Mayring P. Qualitative content analysis: theoretical foundation basic procedures and software solution, 2014. Available: https://nbnresolving.org/urn:nbn:de:0168-ssoar-395173 [Accessed 16 Dec 2018].

52 Schreier M. Qualitative content analysis in practice. London: SAGE, 2012.

53 Tong A, Sainsbury P, Craig J. Consolidated criteria for reporting qualitative research (COREQ): a 32-item checklist for interviews and focus groups. Int J Qual Health Care 2007;19:349-57.
54 Fetters MD, Curry LA, Creswell JW. Achieving integration in mixed methods designs-principles and practices. Health Serv Res 2013;48:2134-56.

55 McCorry NK, Scullion L, McMurray CM. Content validity of the illness perceptions questionnaire-revised among people with type 2 diabetes: a think-aloud study. Psychol Health 2013;28:675-85.

56 Aujla N, Vedhara K, Walker M, et al. Evaluating a Stroke-Specific version of the illness perception Questionnaire-Revised, using the Think-Aloud method. J Health Psychol 2020;25:1989-2005.

57 Curbach J, Apfelbacher C, Knoll A, et al. Physicians' perspectives on implementing the prevention scheme "Physical Activity on Prescription": Results of a survey in Bavaria. Z Evid Fortbild Qual Gesundhwes 2018;131-132:66-72.

58 Brandstetter S, McCool M, Wise M, et al. Australian health promotion practitioners' perceptions on evaluation of empowerment and participation. Health Promot Int 2014;29:70-80.

59 Dillman DA. Mail and telephone surveys: the total design method. New York: Wiley and Sons, 1978.

60 Hoddinott SN, Bass MJ. The dillman total design survey method. Can Fam Physician 1986;32:2366-8.

61 Thorpe C, Ryan B, McLean SL, et al. How to obtain excellent response rates when surveying physicians. Fam Pract 2009;26:65-8.

62 WMA. Wma Declaration of Helsinki - ethical principles for medical research involving human subjects, 1964.

63 WMA. World Medical association Declaration of Helsinki ethical principles for medical research involving human subjects, 2013. 